\title{
Altruism, Cooperation, and Efficiency: Agricultural Production in Polygynous Households
}

\author{
Richard Akresh \\ University of Illinois at Urbana-Champaign \\ Joyce J. Chen* \\ The Ohio State University \\ Charity T. Moore \\ Harvard Kennedy School
}

May 27, 2014

\begin{abstract}
Altruism towards others can inhibit cooperation by increasing the utility players expect to receive in a non-cooperative equilibrium. To test this, we examine agricultural productivity in West African polygynous households. We find cooperation, as evidenced by more efficient production, is greater among co-wives than among husbands and wives. Using a game-theoretic model, we show this outcome can arise because co-wives are less altruistic towards each other than towards their husbands. We present a variety of robustness checks, which suggest results are not driven by selection into polygyny, greater propensity for cooperation among women, or household heads enforcing others' cooperative agreements.
\end{abstract}

JEL Codes: D13, D70, J12, O13, O55

Keywords: Altruism; Non-cooperative behavior; Household bargaining; Polygyny; Africa

\footnotetext{
* Corresponding Author: Department of Agricultural, Environmental and Development Economics, 324 Agricultural Administration Building, 2120 Fyffe Road, Columbus, OH 43210. Email:chen.1276@osu.edu; Phone: (614)2929813. This work has benefited from comments from Ethan Ligon, Steve Wu, Tom Vogl, seminar participants at The Ohio State University and the University of Wisconsin-Madison, and participants of the NEUDC Conference and ASSA Annual Meeting. The authors thank Christopher Udry for graciously sharing his data.
} 


\section{Introduction}

Altruism towards others is thought to aid cooperation, as the inter-dependence of utility functions helps to align incentives and reduce transaction costs. Thus, we should be more likely to observe an efficient allocation of resources among family members because they are altruistic towards each other (Foster and Rosenzweig, 2001). ${ }^{1}$ Pareto efficiency has indeed been confirmed in many studies (Browning and Chiappori, 1998; Chiappori et al., 2002; Bobonis, 2009, Rangel and Thomas, 2012), but a growing body of empirical evidence suggests that households fail to achieve efficiency in production, particularly in the presence of transaction costs (Duflo and Udry, 2004; Goldstein and Udry, 2008; Dubois and Ligon, 2010). However, what is less clear from these studies are the factors that may be inhibiting cooperation.

Fafchamps (2001) proposes several factors that may lead to inefficiency by exacerbating commitment failure, including low gains to cooperation and poor enforcement mechanisms. In this paper, we argue that altruism may, in fact, be a culprit. We model a game involving three players with differing degrees of altruism towards each other and show that stronger altruism can actually encourage players to choose a non-cooperative strategy by increasing the utility that is obtained in the non-cooperative equilibrium and, therefore, reducing both the gains to cooperation and the threat of punishment. The model has several testable implications that we examine using data on agricultural production in Burkina Faso. We control for plot characteristics and household-crop-year fixed effects and examine the variation in yields due to the inefficient allocation of inputs across plots controlled by individuals in the same household planting the same crop in the same year. Based on the game-theoretic model, we focus on efficiency differences across monogamous and polygamous households because the larger role

\footnotetext{
${ }^{1}$ Foster and Rosenzweig (2001) argue that, in environments characterized by imperfect commitment, family members can engage in more complete risk-sharing arrangements.
} 
of shared public goods between husbands and wives, relative to co-wives, also suggests a greater degree of altruism. The empirical evidence supports our model. We find more efficient production, a sign of greater cooperation, among co-wives in polygynous households than among husbands and wives; our point estimates suggest that wives have roughly $80 \%$ higher productivity in polygynous households. This finding highlights the possibility that altruism between parties can inhibit cooperation and lead to less efficient outcomes.

The main empirical concern is that women in polygynous and monogamous households may be different in terms of unobservable characteristics. However, we provide suggestive evidence to show that this potential endogenous selection into polygyny is not likely to be driving the results. Further, a number of robustness checks suggest results are not due to unobserved plot characteristics, endogenous crop choice, stronger preferences (lower costs) for cooperative behavior among women, or the household head serving as an enforcement mechanism for others' cooperative agreements. While our paper focuses on a context in which altruism is prevalent - the household - altruism can similarly alter incentives for cooperation among other parties, such as farmers within a cooperative or members of a rotating saving and credit association.

The remainder of the paper is organized as follows. Section 2 discusses the socio-cultural context and household arrangements in Burkina Faso. Section 3 presents a game-theoretic model of interactions within polygynous households. Section 4 describes the data and empirical strategy and presents the main results, along with several robustness checks. Section 5 concludes.

\section{Households in Burkina Faso}

Intrahousehold dynamics in rural Burkina Faso are complex. Households cultivate several rainfed, primarily subsistence crops on multiple plots, with each plot controlled by different 
household members. Married women often have access to private plots under their own control (Kevane and Gray, 1999). ${ }^{2}$ Control over plots includes decision-making over crop choice, timing and quantity of inputs, and output ownership (Guyer, 1986; Fafchamps, 1993; Udry, 1996). This access to land does not relieve women of their responsibility to contribute labor to household fields for joint production (Dey, 1997), which typically takes precedence over females’ work on their own fields (van Koppen, 1990). While household heads are assumed to provide staple foods and cover medical expenses and school fees, in practice, females often have to supply their own crops as food or cover expenses. A single household may include multiple mother-child pairs (Thorson, 2002), but each husband/wife pair is viewed as a separate entity (Boye et al., 1991). ${ }^{3}$ Mother-child pairs typically live in their own nuclear units, and wives are responsible for primary caretaking activities for their own children. ${ }^{4}$ Co-wives occupy various positions of power in the household, with the first wife typically holding the most power of the wives.

Much of the anthropological literature suggests that co-wife relationships are characterized by conflict. Jankowiak et. al. (2005) find this to be true in almost all of the 69 polygynous cultures they review. Despite this near-universal trait, they note the tendency for cowives to cooperate to achieve pragmatic goals, particularly if females are not as reliant on their husbands for material or emotional support. This was suggested earlier by Becker (1981), who applied his Rotten Kid Theorem to polygamous households to suggest that cooperation could occur in productive activities, while conflict might still occur over distribution. Given that

\footnotetext{
${ }^{2}$ Wives' plot locations and sizes are determined by the husband, often at the time of marriage, while private plots of other household males are usually intended to allow the male to accumulate wealth to eventually break off to form his own household (Diallo and Nagy, 1986).

${ }^{3}$ Compounds are the major social unit of organization, overseen by the male lineage head. Inside compounds are one or more households headed by males who have single and married male dependents and numerous hearth-holds comprised of widows, wives, wives of non-resident migrants, daughters-in-law, and single children (Thorson, 2002). ${ }^{4}$ Other female duties include retrieving water and wood, doing domestic chores, and income generating activities such as selling millet beer or food products (Diallo and Nagy, 1986). In general, each wife prepares daily meals for her own children, with a rotation system among wives for preparing for the husband.
} 
women in Burkina Faso have been found to work significantly more hours per day than male household members (Saito, 1994), cooperation by co-wives in polygynous households could be an important method for them to manage demands on time and energy, even if they do not necessarily care about the utility of the other wives. Indeed, in rural areas of the Sahel, polygyny can serve to reduce a co-wife's daily responsibilities by allowing women to engage in laborsharing activities (Boye et al., 1991). Members of the same household often exchange goods or services through involved agreements that are driven by local norms and customs (Saito, 1994).

Several papers test for productive efficiency within African households, although none focus on the distinction between monogamous and polygynous households. Peterman et al. (2011) find lower productivity on female-controlled plots in Uganda and Nigeria, even after controlling for crop choice, agricultural inputs, socioeconomic background, and household fixed effects. Pareto inefficient outcomes have also been observed in fallow times in Ghana, a result attributed to the role of ambiguous property rights and individual political power (Goldstein and Udry, 2008). As households in the region are often organized along gendered production spheres, observation of non-cooperative outcomes is not entirely surprising.

Using International Crops Research Institute for the Semi-Arid Tropics (ICRISAT) data, Udry (1996) finds that, among similar plots planted with the same crop in the same year within a given household, female-controlled plots achieve significantly lower yields than male-controlled plots. His analysis reveals that households use inputs inefficiently: female-controlled plots use less male labor and manure, suggesting that husband-wife cooperation to reallocate household resources would yield larger output for the family. Akresh (2008) shows that these production inefficiencies within households are muted in the face of adverse shocks, perhaps because the gains to cooperation are larger when household food security is threatened. Nevertheless, when 
Rangel and Thomas (2012) test whether household consumption decisions are Pareto efficient, they cannot reject efficiency in West African households.

Inefficiency within the household has also been found along other dimensions. Kazianga and Wahhaj (2013) reject Pareto efficiency among the household head, junior males, and females but do not consider differences across monogamous and polygynous households. Kazianga and Klonner (2009) examine child survival in Mali but cannot reject efficiency in monogamous households. However, they find evidence of differential child survival for junior wives and suggest that co-wife competition and the junior wives' weaker bargaining position drive this inefficient result. Mammen (2009) finds some education-related outcomes are worse for children of junior wives, but she cannot reject a collective bargaining model that allows credit constraints.

\section{Modeling Cooperation in Polygynous Households}

The notion that altruism can reduce efficiency was first formally suggested by Bernheim and Stark (1988). They note that, when altruism improves the static non-cooperative outcome, it also weakens the severity of punishments, making cooperative behavior and the efficient allocation of resources more difficult to sustain. Our model follows this premise but allows for three players within the same family to have differing degrees of altruism towards each other. The advantage of this formulation is that, when we empirically test the model, we can control for features of the household that may be correlated with altruism but also facilitate cooperation independently, such as capacity for monitoring/punishment or expectations about future interactions. We show that, when altruism between two players improves the non-cooperative outcome, it also reduces the gains to cooperation ceteris parabis. We then show, more importantly, that altruism can reduce the scope for punishment, making cooperative agreements either unsupportable or vulnerable to renegotiation when commitment is imperfect. In Section 3.1, we lay out the basic 
utility and production functions. We then describe the stage game (Section 3.2) and the repeated game with limited commitment (Section 3.3).

\subsection{Theoretical Framework}

Consider a polygynous household with a husband $(h)$ and two wives ( 1 and 2$)$. Each individual has preferences over own consumption of two goods ( $x$ and $z$ ). Husbands and wives derive utility from each other's consumption of good $z$, but co-wives exhibit no altruism towards each other. ${ }^{5}$

$$
U_{h}=U_{h}\left(x_{h}, z_{h}, z_{1}, z_{2}\right) \text { and } U_{i}=U_{i}\left(x_{i}, z_{i}, z_{h}\right) \forall i \in\{1,2\}
$$

Note that our characterization of altruism follows that of Fehr and Schmidt (2006), in which the utility of an individual is increasing in the consumption of another person (other people). Preferences are not functionally interdependent, as each player cares only about the final allocation of resources and not how that allocation was reached or the utility of the other players.

The feature of the $z$ good that drives the main implications of the model is that the altruist cannot purchase it directly or, more generally, the altruist and the subject face different (implicit) prices for the same good. ${ }^{6}$ Thus, even with interdependent preferences ( $U_{j \neq i}$ enters the utility function of $i$ ), the main implications of the model will still hold, provided the altruist does not fully internalize the effect of his actions on other(s). ${ }^{7}$ This is similar to the separate spheres assumption in Lundberg and Pollak (1993) and is consistent with common forms of altruism (e.g., preferences for the utility of one’s spouse, parents’ preferences for children’s future earnings, preferences for the well-being of individuals in another group). If we think of $z$ as child “quality”, this assumption is also consistent with anthropological descriptions of Burkinabé

\footnotetext{
${ }^{5}$ It would be sufficient to assume that altruism between husbands and wives is stronger than that between co-wives.

${ }^{6}$ Note that, if both players can purchase the public good at the same price and both make strictly positive contributions, an efficient allocation of resources can be achieved even without explicit cooperation among players (Warr, 1983 and Bergstrom et al., 1986).

${ }^{7}$ In other words, at the point where utility is maximized, the marginal utility derived from others' consumption is less than the marginal utility derived from own consumption: $\left.\partial U_{i} / \partial U_{j \neq i}<\min \left[\partial U_{i} / \partial x_{i}, \partial U_{i} / \partial z_{i}\right]\right)$.
} 
households, with wives having ultimate control over the care of their own children. More generally, we could think of $z$ as a vector, with some elements being private goods that provide derived utility (e.g., aesthetic appearance of spouse) and other elements being public goods for the conjugal unit (child quality). Moreover, a subset of the $z$-vector (e.g., meals, childcare) may overlap across family members, including co-wives, such that each individual possesses the ability to purchase some, but not all, $z$-goods directly.

On the production side, each individual operates one plot of agricultural land. Farm production utilizes both male labor $\left(N^{M}\right)$ and female labor $\left(N^{F}\right) .{ }^{8}$ Although all individuals have access to the same production technology, they are endowed with plots with different characteristics (e.g., size, soil type, toposequence), denoted $A$, that affect the optimal input mix. Denote each individual's production function as follows:

$$
Y_{i}=Y\left(N^{M}, N^{F} ; A_{i}\right)
$$

Farm production is the only source of income, with the price of output normalized to one, and each individual supplies one unit of labor inelastically.

\subsection{Basic Stage Game}

The action space for each player includes own consumption and labor allocations to own plot and other players' plots $\left\{x_{i}, z_{i}, N_{i}^{i}, N_{i}^{j}, N_{i}^{k}\right\}$ where $N_{i}^{j}$ represents player $i$ 's labor allocated to player j's plot. Each player has two strategies - cooperate and don't cooperate - when interacting with each of the other players. When players $i$ and $j$ cooperate, they maximize a joint objective function. Therefore, we can treat their production and consumption decisions as

\footnotetext{
${ }^{8}$ Our data show almost no overlap in the agricultural tasks performed by males and females, suggesting that male and female labor are imperfect substitutes in agricultural production. The degree of substitutability is not central to the key implications of our model. In fact, assuming imperfect substitutability broadens the range of parameter values for which altruism will discourage cooperation. This is because imperfect substitutability increases the gains to cooperation without affecting the scope for punishment, relative to cooperating with a non-altruistic player.
} 
separable and sequential. The pair first maximizes joint output on their plots, treating the labor allocations and consumption choices of the third player $(k)$ as fixed.

$$
\begin{array}{r}
\max _{N_{i}^{i}, N_{i}^{j}, N_{j}^{i}, N_{j}^{j}} Y\left(N_{i}^{i}, N_{j}^{i}, N_{k}^{i} ; A_{i}\right)+Y\left(N_{i}^{j}, N_{j}^{j}, N_{k}^{j} ; A_{j}\right) \\
\text { subject to } N_{i}^{i}+N_{i}^{j}+N_{i}^{k}=1 \text { and } N_{j}^{i}+N_{j}^{j}+N_{j}^{k}=1
\end{array}
$$

They then maximize a joint utility function, in order to coordinate their choices of $z^{9}$

$$
\begin{aligned}
\max _{x_{i}, z_{i}, x_{j}, z_{j}} \lambda U_{i}(\cdot)+(1-\lambda) U_{j}(\cdot) & \\
& \text { subject to } x_{i}+x_{j}=Y_{i}+Y_{j}-p_{i} z_{i}-p_{j} z_{j}, U_{i} \geq \widehat{U}_{\imath} \text { and } U_{j} \geq \widehat{U}_{J}
\end{aligned}
$$

where $p$ denotes the relative price of the public good, and $\wedge$ denotes the utility each player obtains outside the cooperative agreement. The parameter $\lambda$ determines how the gains from cooperation are distributed. Based on this optimization, the cooperative agreement then stipulates plot-specific labor allocations ${ }^{10}$ for each player, as well as a (net) payment from $j$ to $i, R_{i}^{j}$, (with $R_{i}^{j}=-R_{j}^{i}$ ) in order to facilitate the purchase of the specified individual consumption bundles.

If player $i$ does not cooperate with player $j$, he/she chooses consumption and labor allocations to maximize his/her utility, subject to the income generated on her plot and taking into account the other players' response functions (or cooperative agreements), denoted by *:

$$
\max _{N_{i}^{j}, N_{i}^{k}, z_{i}} U_{i}(\cdot) \text { subject to } x_{i}=Y\left(1-N_{i}^{j}-N_{i}^{k}, N_{j}^{i}, N_{k}^{i} ; A_{i}\right)-p_{i} z_{i}
$$

$$
\text { where } N_{s}^{i}=N_{s}^{i^{*}}\left(N_{i}^{s}, N_{k}^{s} ; \mu_{s}, p_{s}, A_{s}\right) \text { and } z_{s}=z_{s}^{*}\left(N_{i}^{s}, N_{k}^{s} ; \mu_{s}, p_{s}, A_{s}\right) \text { for } s=j, k
$$

and $\mu$ represents parameters of the utility function. For now, we assume cooperative agreements are fully binding and there are no transaction costs associated with cooperation. Thus, if there are

\footnotetext{
${ }^{9}$ Since co-wives have no shared goods and their utility functions are independent, maximization of a joint utility function is equivalent to co-wives separately maximizing their own utility functions.

${ }^{10}$ Labor-sharing is the primary source of cooperation in our model. However, the model's key implications are unaffected by the existence of labor markets, provided those markets are imperfect as is likely the case in our empirical setting.
} 
gains to cooperating with another player, then cooperation with that player will be a dominant strategy. In the absence of transaction costs, each player's best response is unaffected by whether the other players are cooperating, provided cooperation with one player does not completely eliminate all gains to cooperating with the other player. ${ }^{11}$

Multiple equilibria are clearly possible with this general set-up, depending on the payoffs associated with cooperation for each pair. We wish to highlight here that the gains to cooperation for altruistic players (husband and wife) may be less than for non-altruistic players (co-wives). That is, the surplus that is generated, above and beyond the non-cooperative equilibrium, may be greater when co-wives cooperate if, as is suggested in the anthropological literature (Dey 1997), husbands and wives pool some resources even in the absence of an explicit cooperative agreement, whereas co-wives do not. Altruistic preferences make it more likely that husbands and wives engage in some minimal exchange behavior even when no cooperative agreement is reached. ${ }^{12}$ Put another way, in the absence of cooperative agreements, each husband-wife pair is closer to the Pareto frontier for agricultural production than is the wife-wife pair. To see this, consider the husband's maximization problem in the absence of a cooperative agreement:

$$
\begin{aligned}
& \max _{N_{M}^{1}, N_{M}^{2}, z_{h}} U_{h}\left(x_{h}, z_{h}, z_{1}, z_{2}\right) \text { subject to } x_{h}=Y_{h}\left(1-N_{M}^{1}-N_{M}^{2}, N_{1}^{M}+N_{2}^{M} ; A_{h}\right)-p_{h} z_{h} \\
& \text { where } N_{i}^{M}=N_{i}^{M^{*}}\left(N_{M}^{i}, N_{j}^{i} ; \mu_{i}, p_{i}, A_{i}\right) \text { and } z_{i}=z_{i}^{*}\left(N_{M}^{i}, N_{1}^{i}+N_{2}^{i} ; \mu_{i}, p_{i}, A_{i}\right) \text { for } i=1,2
\end{aligned}
$$

From the first order condition,

$$
\frac{\partial U_{h}}{\partial z_{i}} \frac{\partial z_{i}^{*}}{\partial N_{M}^{i}}=\frac{\partial U_{h}}{\partial x_{h}}\left(\frac{\partial Y_{h}}{\partial N_{M}^{i}}+\frac{\partial Y_{h}}{\partial N_{i}^{M}} \frac{\partial N_{i}^{M^{*}}}{\partial N_{M}^{i}}\right) \text { for } i=1,2
$$

\footnotetext{
${ }^{11}$ If there are transaction costs associated with cooperation or cooperation with one player reduces the gains to cooperating with the other player, this could create an equilibrium in which two players cooperate while the third is excluded. An earlier working paper version of this paper examines this case in more detail.

12 Note that mutual altruism is not necessary and, in fact, makes the proposed equilibrium more difficult to sustain, as it increases the gains to husband-wife cooperation. As long as the husband is altruistic toward the wife, he will share resources with her, and the gains to cooperation for the wife will always be less when dealing with her husband than when dealing with her co-wife.
} 
we see that the optimal allocation of labor to wife $i$ 's plot is strictly greater than zero, as long as the husband's marginal utility of $z_{i}$ exceeds his marginal utility of $x$ and the wife's choice of $z$ is increasing in the labor he allocates to her plot. Moreover, in the absence of a cooperative agreement, the husband's allocation of labor will not be efficient because production and consumption decisions are not separable. To see this, rewrite the above condition as:

$$
\frac{\partial U_{h}}{\partial z_{i}} \frac{\partial z_{i}^{*}}{\partial Y_{w_{i}}}\left(\frac{\partial Y_{w_{i}}}{\partial N_{M}^{i}}+\frac{\partial Y_{w_{i}}}{\partial N_{i}^{i}} \frac{d N_{i}^{i}}{d N_{M}^{i}}+\frac{\partial Y_{w_{i}}}{\partial N_{j}^{i}} \frac{d N_{j}^{i}}{d N_{M}^{i}}\right)=\frac{\partial U_{h}}{\partial x_{h}}\left(\frac{\partial Y_{h}}{\partial N_{M}^{i}}+\frac{\partial Y_{h}}{\partial N_{i}^{M}} \frac{\partial N_{i}^{M^{*}}}{\partial N_{M}^{i}}\right)
$$

For the marginal product of the husband's labor to be equalized across plots, the marginal rate of transformation between $x$ and $z$, in utility terms, must be equal to one, both wives' labor allocations to wife $i$ 's plot must be independent of the husband's labor allocation, and wife $i$ 's labor allocation to her husband's plots must be independent of his allocation to her plot. Each wife solves:

$$
\begin{aligned}
& \max _{N_{i}^{M}, N_{i}^{j}, z_{i}} U_{w_{i}}\left(x_{i}, z_{i}, z_{h}\right) \text { subject to } x_{i}=Y_{i}\left(N_{M}^{i},\left(1-N_{i}^{M}-N_{i}^{j}\right)+N_{j}^{i} ; A_{i}\right)-p_{i} z_{i} \\
& \text { where } N_{M}^{i}=N_{M}^{i}{ }^{*}\left(N_{i}^{M}, N_{j}^{M} ; \mu_{M}, p_{M}, A_{M}\right), \quad N_{j}^{i}=N_{j}^{i^{*}}\left(N_{i}^{j}, N_{M}^{j} ; \mu_{j}, p_{j}, A_{j}\right) \\
& \qquad \text { and } z_{h}=z_{h}{ }^{*}\left(1-N_{M}^{i}-N_{M}^{j}, N_{i}^{M}+N_{j}^{M} ; \mu_{h}, p_{h}, A_{h}\right)
\end{aligned}
$$

which gives us the following first order condition for $N_{i}^{M}$ for an interior solution:

$$
\frac{\partial U_{w_{i}}}{\partial x_{i}}\left(\frac{\partial Y_{i}}{\partial N_{i}^{M}}+\frac{\partial Y_{i}}{\partial N_{M}^{i}} \frac{\partial N_{M}^{i}{ }^{*}}{\partial N_{i}^{M}}\right)+\frac{\partial U_{w_{i}}}{\partial z_{h}} \frac{\partial z_{h}{ }^{*}}{\partial N_{i}^{M}}=0
$$

The wife will provide labor on her husband's plot as long as he provides enough labor to offset the decline in her production, net of the utility gain she receives via the husband's increased consumption of $z$. Both spouses should benefit from this arrangement if, in the absence of laborsharing, the marginal product of own labor is lower on own plots than on spouses' plots. Note that, when maximizing own utility, co-wives will not provide labor on each other's plots because 
they do not expect reciprocity. However, as long as the husband and wife are at an interior solution, her labor allocation will be responsive to his choices. Thus, although the husband and wife supply labor on each other's plots even in the absence of an explicit cooperative agreement, they do not reach an efficient outcome. This result is sensitive to the separate spheres assumption and is a result of the husband and wife not being able to purchase each other's $z$-goods directly.

\subsection{Repeated Game with Limited Commitment}

In the absence of transaction costs, a Pareto efficient outcome is feasible, with all three players cooperating and pooling labor. However, we must also consider the possibility that players may renege on established cooperative agreements. Because each player retains control over the output produced on his/her own plot (as is consistent with the anthropological literature from West Africa), it is possible to renege on both the labor allocated to others' plots and the payment $R$. With limited enforcement, cooperation cannot be sustained in a one-shot (or finitely repeated) game. However, if the stage game is repeated infinitely and players are sufficiently forwardlooking, then Nash reversion (Friedman, 1971) may be used to sustain cooperative agreements. First, consider the punishment phase in which the players revert to their non-cooperative Nash strategies for a predetermined number of periods. In this equilibrium, altruism between the husband and wife leads to some strictly positive labor-sharing, even though wife $i$ does not share labor with her co-wife. But if, as shown above, the gains to cooperating with the co-wife exceed the gains to cooperating with the husband, then, under Nash reversion, wife $j$ can hold wife $i$ to a more severe punishment than can her husband.

Next, consider a deviation by player $i$ from the equilibrium in which all players behave cooperatively. When deviating from a cooperative agreement with player $j$, player $i$ withholds both labor as well as any positive payments owed to player $j\left(R_{j}^{i^{*}}<0\right)$, while the other players 
continue to provide the agreed-upon payments and/or labor on player $i$ 's plot. Total income for player $i$, conditional on reneging on his/her agreement with player $j$, is then

$$
\bar{V}_{i}=\bar{Y}_{i}+\left|R_{j}^{i^{*}}\right|+R_{i}^{k^{*}}
$$

where $\bar{Y}_{i}$ is the output player $i$ produces by sharing labor with player $k$ but not player $j$ and $R^{*}$ denotes the payment stipulated by the cooperative agreement. The payoff is positively correlated with the surplus that would have been generated by cooperation, because the sum of $\bar{Y}_{i}$ and $R_{j}^{i^{*}}$ is (weakly) increasing in the quantity of labor to be shared. Then, because the gains to cooperating with a co-wife are greater, the gain to deviating from an agreement with the co-wife should also be greater. However, when wife $i$ deviates from a cooperative agreement with the husband, she allocates strictly less labor to his plot than she would in the Nash equilibrium. Therefore, the gain in output is greater when deviating against the husband than the co-wife. Moreover, the more labor-sharing there is in the one-shot Nash equilibrium, the greater are the gains to deviating.

When wife $i$ deviates from a cooperative agreement with her husband, towards whom she is altruistic, she is penalized via a reduction in her husband's consumption of $z$. Though the optimal deviation involves less labor-sharing than the Nash strategy, she will not supply zero labor on her husband's plot (whereas labor-sharing with the co-wife is exactly zero under the Nash strategy). Under the optimal deviation, the value of the marginal unit of own labor on wife $i$ 's plot just offsets the loss from her husband's reduced consumption of $z$ (see condition [3]). Thus, whether wife $i$ deviates against her husband or co-wife, in both cases she is able to fully capture the value of the other's labor to her plot as well as the labor she should have allocated to his/her plot, although she converts the income gains into utility with different bundles of goods. Deviating against the husband will, therefore, yield both greater income and greater utility than 
deviating against the co-wife, while the threat of punishment from the husband is weaker. ${ }^{13}$ Altruism between the husband and wife makes cooperation more difficult to sustain.

Alternatively, we can consider a min-max punishment strategy, in which the husband punishes a deviation by wife $i$ by allocating zero labor to her plot until she again plays cooperatively. This would be a more severe punishment than Nash reversion and could be sufficient to sustain cooperation, but it is not weakly renegotiation-proof (Abreu et al. 1993). Once in the punishment phase, both the husband and wife $i$ would be better off playing the Nash equilibrium. Because of the altruistic linkage between the two, the husband's utility is increasing in the wife's payoff and, therefore, there does not exist a tit-for-tat punishment that rewards the husband while min-maxing wife $i .{ }^{14}$ We could consider a tit-for-tat punishment in which the husband receives at least his Nash payoff as well as a side payment from the wife - consisting of his private good, the public good or a combination of the two - at the expense of her own private consumption. However, the wife will be tempted to renege in the punishment phase and, if she were to do so, the strongest punishment the husband could invoke would be the min-max strategy. Thus, this equilibrium would also unravel with renegotiation.

In summary, we have shown the existence of an equilibrium in which co-wives cooperate with each other but not with their husband. Altruism between the husband and each wife makes that equilibrium more likely for two reasons. First, altruism facilitates exchange behavior even in the absence of an explicit agreement. This reduces the gains to cooperation, increases the gains to deviating from a cooperative agreement, and reduces the severity of any punishment that may be imposed. Thus, in the presence of limited commitment, a non-altruistic party (a co-wife) is

\footnotetext{
${ }^{13}$ If the husband and wife $j$ can jointly punish wife $i$ for deviating from either agreement, then cooperation among all three players could be sustained. However, joint punishment is not subgame-perfect, as wife $i$ can always offer wife $j$ a higher pay-off by deviating from the joint punishment to co-wife cooperation.

${ }^{14}$ As a result of this temptation to renegotiate, the husband also cannot achieve a cooperative outcome by "delegating” the enforcement of cooperative agreements to a non-altruistic third party.
} 
better able to prevent deviations from the cooperative agreement and, therefore, better able to sustain cooperation. Second, even if the altruistic party is willing to impose severe punishments, these will not be renegotiation-proof because altruism makes it impossible to punish the deviating player while rewarding the cooperating player. Thus, payoffs in the punishment phase will be Pareto-dominated by the Nash equilibrium. These results are sensitive to our separate spheres-type assumption that, based on the anthropological evidence discussed above, is an accurate representation of Burkinabé households. Moreover, the notion of a good over which one has preferences but no direct control is consistent with many formulations of altruism. The basic framework and implications can, therefore, be applied to a variety of contexts, even though they have been derived from a very specific case.

\section{Empirical Application}

\subsection{Testable Implications}

To generate testable implications from our theoretical model, recall that cooperation maximizes joint farm production such that variations in yield and input use across plots are functions of only plot characteristics (Udry, 1996). This implies that, controlling for land quality, crop choice, and shocks to the production process, yields should be unaffected by cultivator characteristics. We estimate plot yield as a function of plot area, soil type, toposequence, location, and cultivator characteristics (gender, relation to household head - head, wife, or other) conditional on a household-crop-year fixed effect. That is, we examine the deviation of plot yield from mean yield as a function of the deviation of plot characteristics from mean plot characteristics within a group of plots planted with the same crop by members of the same household in a given year. Yield $Q$ for plot $i$, planted with crop $c$, in year $t$, in household $h$ is expressed as:

$$
Q_{h t c i}=\boldsymbol{X}_{h t c i} \beta+\gamma_{G} G_{h t c i}+\gamma_{O M} O M_{h t c i}+\gamma_{O F} O F_{h t c i}+\lambda_{h t c}+\varepsilon_{h t c i}
$$


where $\boldsymbol{X}$ is a vector of plot characteristics, $G$ is gender of the plot cultivator (1=female), $O M$ and $O F$ are indicators equal to one if the plot cultivator is an "other male" (not the household head) or an "other female" (not a wife of the head), respectively, $\lambda$ is a household-crop-year fixed effect, and $\varepsilon$ is an error-term. Cultivator characteristics (gender and relationship to household head) ${ }^{15}$ are allowed to differ for polygynous households via an interaction with an indicator for polygyny (Poly), with $\gamma_{k}=\gamma_{k}^{0}+\left(\right.$ Poly $\left._{h t} * \gamma_{k}^{P}\right)$ for $k=G, O M, O F \cdot{ }^{16}$ Note that our empirical tests focus on efficiency within the household rather than productivity. Clearly, monogamous and polygynous households, as well as individual cultivators within those households, may differ in their levels of productivity, but the degree of cooperation will be evidenced by the efficiency with which inputs are allocated, given household-specific constraints on technology, access to inputs, and obligations to family/clan.

The interaction of polygyny and cultivator characteristics indicates how the variation in yields between cultivators differs across monogamous and polygynous households. We can attribute this difference to the causal effect of additional wives as long as the household-cropyear fixed effects account for unobserved characteristics that are correlated with both conjugal status and the difference in yields between cultivator types, conditional on planting the same crop, in the same year, in the same household. In Sections 4.3-4.5, we test the robustness of this strategy by considering selection into polygyny, unobserved plot characteristics, and endogenous crop choice.

For a negative coefficient on gender, a positive coefficient on the interaction of polygyny and gender then indicates that the husband-wife yield differential is smaller for husbands with

\footnotetext{
${ }^{15}$ Unfortunately, the data do not link agricultural plots to individual identifiers, so we are unable to identify specific characteristics about a plot's cultivator (age, senior/junior wife status, or specific relationship to the head or to other household members).

${ }^{16}$ Akresh et al. (2012) use a similar specification but do not differentiate "other” cultivators by gender.
} 
multiple wives. This may be indicative of cooperation among co-wives or (greater) cooperation between husbands and wives. To differentiate these, we examine how polygyny affects the yield differential between husbands and other cultivators. A decline in other cultivators’ yields, relative to the household head, suggests that the head himself is also able to achieve a more efficient allocation of agricultural inputs in the presence of multiple wives, whereas an increase in other cultivators' yields, relative to the head, suggests that wives cooperate more with each other (and perhaps with other cultivators) than with the head.

By including indicators for the relationship of the cultivator to the household head, we can also examine other opportunities and incentives for cooperation among household members. In Section 3, we argue that a positive coefficient on the interaction between polygyny and gender is the result of greater altruism between husbands and wives than between co-wives. However, we would observe the same result if the cost of cooperation is lower among women and not just co-wives. In this case, the presence of additional women, due to polygyny, should facilitate greater cooperation among all women and reduce differences in yields between wives and other female cultivators. Alternatively, in polygynous households, the household head may be able to enforce an optimal allocation of agricultural inputs among other household members' plots, even when he is unable to enforce cooperative arrangements between himself and his wives, because he can act as a third-party monitor/arbitrator. In this case, the head should be able to enforce cooperation between other cultivators within the household as well, resulting in smaller yield differences among other cultivators who are not the household head or wives.

These hypotheses about dynamics, summarized in the table below, allow us to distinguish between alternative explanations for smaller male-female yield differentials in polygynous households. The altruism explanation is consistent only with the first row. However, if women 
prefer to cooperate with each other over men, we will observe a smaller yield differential between wives and other females in polygynous households as well as smaller yield differentials between men and women in polygynous households. Alternatively, if the head enforces cooperative arrangements among other cultivators, then we should observe cooperation between co-wives in conjunction with cooperation between other cultivator pairs.

\begin{tabular}{ll}
\hline \multicolumn{1}{c}{ Hypothesis } & \multicolumn{1}{c}{ Testable Implication } \\
\hline $\begin{array}{l}\text { Greater cooperation among } \\
\text { co-wives than among } \\
\text { husbands and wives }\end{array}$ & $\begin{array}{l}\text { Smaller yield differential between husbands and wives in the } \\
\text { presence of multiple wives, and smaller or unchanged yield } \\
\text { differential between husbands and other male cultivators } \\
\gamma_{G}^{P}>0 \text { and } \gamma_{O M}^{P} \geq 0\end{array}$ \\
$\begin{array}{l}\text { Greater cooperation among } \\
\text { women than among men }\end{array}$ & $\begin{array}{l}\text { Smaller yield differential between wives and other female } \\
\text { cultivators in the presence of multiple wives (more women) } \\
\gamma_{G}^{P}>0 \text { and } \gamma_{O F}^{P}>0\end{array}$ \\
$\begin{array}{l}\text { Household head enforces } \\
\text { others' cooperative } \\
\text { arrangements }\end{array}$ & $\begin{array}{l}\text { Smaller yield differential between other male cultivators and } \\
\text { other female cultivators than between husbands and wives } \\
\gamma_{G}^{P}>0 \text { and } \gamma_{O M}-\gamma_{O F}<0\end{array}$ \\
\hline
\end{tabular}

\subsection{Empirical Results}

We use the 1984-85 ICRISAT Burkina Faso household survey, which covers 150 households in 6 villages across 3 provinces: Djibo, Yako, and Boromo (see Matlon, 1988 and Udry, 1996 for detailed descriptions of the data). 50.7 percent of households are polygynous, defined as the household head having two or more wives. Of these households, 56\% have two wives, $33 \%$ have three wives, and $11 \%$ have four or five wives. ${ }^{17}$ For household heads and other female non-wife cultivators, average yields are lower in polygynous households, although average plot size is similar (Table 1). For wives and other males, yields are slightly higher and plots somewhat larger

\footnotetext{
${ }^{17}$ We classify households as polygynous based on the number of wives in the household roster because household heads were not asked about marital status. If there are wives of the head living outside the household at the time of the survey, we could mistakenly classify the household. However, migration of wives is rare. In our data, only $6 \%$ of migrants are wives and, of these, the majority are listed in the household roster. In addition, we use the 1993 Demographic and Health Survey to construct both definitions of polygyny (reported and observed number of wives) and find only a 2 percentage point difference in the implied polygyny rate, further suggesting that our classification is accurate.
} 
in polygynous households. The percentage of plots planted with a given crop differs, with wives in polygynous households devoting a larger fraction of plots to millet and sorghum (staple crops) and a smaller percentage to okra and earthpeas/fonio. This suggests polygynous households may use a different cropping strategy, although some of the difference may be due to agro-climatic variation that coincides with differences in polygyny rates across Burkina Faso. ${ }^{18}$

Column I of Table 2 replicates the household-crop-year fixed effects specification in Udry (1996) using only 1984-85 data. ${ }^{19}$ We find a negative and significant effect of cultivator gender on plot yield, but the magnitude is larger than in Udry. In part, the difference is due to the ICRISAT survey design. In 1981-83 (the data used in Udry's analysis), detailed information was collected for a sub-sample of plots (all cereal, cotton, and root crops, but only one plot of the household head and senior wife for legumes/garden crops), but information for all plots was collected in 1984-85 (Matlon 1988). Because we are interested in the yields of other cultivators, particularly co-wives, and wives devote a greater share of plots to legumes/garden crops, the 1981-83 data suffer from significant sample selection and are therefore excluded from our analysis. In column II, we add indicators for other male and other female cultivators within the household. The coefficient on gender is still statistically significant and similar in magnitude. Other male cultivators have significantly lower yields relative to the household head, suggesting inefficiencies in intrahousehold allocation arise along dimensions other than gender. In column III, we add interactions of polygyny with cultivator characteristics and, to allow for differences

\footnotetext{
${ }^{18}$ The Djibo region is well-suited to millet and fonio but not white sorghum, and respondents in this region are predominantly Rimaibe with a low incidence of polygyny. The Yako region is well-suited to white sorghum, millet and cotton, and respondents in this region are predominantly Mossi with a high incidence of polygyny. The Boromo region is better suited to sorghum and maize than millet, and respondents are predominantly Dagari and Bwa, both with high incidences of polygyny (see Matlon, 1988).

${ }^{19}$ In addition to including household-crop-year fixed effects, all regressions control for plot size (by decile), soil type, toposequence, and location.
} 
in technology across household types, with all plot characteristics. ${ }^{20}$ Relative to the head, wives in polygynous households have significantly higher yields than wives in monogamous households, and the same is true for other males. This is consistent with greater cooperation among co-wives than among husbands and wives. The point estimate for $\gamma_{O F}^{P}$ is consistent with stronger preferences for cooperation among women but is not statistically significant, and there is no significant difference between wives and other females to begin with. We do not find evidence of the household head acting as an enforcement mechanism; although the point estimates are consistent with that story, we cannot reject the hypothesis that the coefficients on other male and other female are equal $(p$-value $=0.196)$. Thus, while we do not find evidence in favor of these alternative explanations, we cannot yet completely rule them out. ${ }^{21}$

To provide additional evidence to distinguish these hypotheses, we limit estimation in Table 3 to specific cultivator pairs. Identification relies on variation in yields across plots planted with the same crop, in the same year, in the same household, between only two types of cultivators, rather than all four types. In column I, polygyny reduces the male-female differential even when the sample is limited to plots cultivated by the head and his wife (wives). Focusing on plots cultivated by other males and other females (column II) shows that yield differences are nearly identical to those between husbands and wives, providing more conclusive evidence that heads are not enforcing cooperation among other cultivators, in either monogamous or polygynous households. Limiting the estimation to only male cultivators (column III), we again find that the difference in yields between the head and other males is significantly smaller in

\footnotetext{
${ }^{20}$ We reject the hypothesis that the interactions of polygyny with plot characteristics are not jointly significant, $(p-$ value $=0.000$ ), so we include them in all specifications that distinguish monogamous and polygynous households.

${ }^{21}$ We discuss the Table 2 column IV results after Table 3.
} 
polygynous households. Polygyny allows other male cultivators to narrow the gap, relative to the head, which suggests that husbands' yields do not benefit (disproportionately) from polygyny. ${ }^{22}$

However, limiting the analysis to female plots does not rule out a greater propensity for cooperation among women generally. Yields for other female cultivators are not significantly different from those for wives of the head, in either type of household (column IV). To test this more directly, we look at how the presence of another female cultivator, not a wife of the head, affects efficiency in the household. In effect, we compare the male-female yield differential across households that do and do not have an "other female" cultivator. We limit this estimation to household heads and wives to ensure the coefficients on the gender variable and its interactions are not driven by the behavior of the other female cultivators themselves. In column $\mathrm{V}$, we see that the presence of an additional female cultivator significantly increases the difference in yields between husbands and wives, and polygyny again eliminates this gap, although the point estimates are imprecise. There may be multiple explanations for this, and the presence of an additional female cultivator may not be exogenous, even conditional on the household-year fixed effect. Nonetheless, the results are not consistent with stronger preferences for cooperation among all women; rather, the identity of the "additional" woman - wife of the head or other female - determines whether her presence will worsen or improve allocative efficiency within the household.

Our model shows that cooperation between altruistic parties can actually be more difficult to sustain than that between purely self-interested parties. We test this by comparing the male-female yield gap across monogamous and polygynous households, where polygyny represents the addition of a potential collaborator with altruistic preferences towards the husband

\footnotetext{
${ }^{22}$ Note that this does not necessarily imply that polygynous household heads are less productive than other male cultivators in the same household, only that they receive fewer inputs relative to other male cultivators, compared to monogamous households.
} 
but not the co-wife. However, this contrast between husband-wife and co-wife interaction provides a second testable implication: the likelihood of cooperation should be declining in the degree of altruism between players. If altruism is, at least in part, based on children as a shared public good, then we should see greater cooperation (smaller yield differences) among couples who have fewer children and, therefore, fewer shared goods. Consistent with this, the interaction of gender and the number of children of the head currently living in the household is negative and significant (column IV, Table 2), and the direct effect for female cultivators is now not statistically significant. This suggests that there is no statistical difference in yields between husbands and wives when there are no children in the home - i.e., when they do not share public goods, particularly those that tend to fall into separate production spheres.

In polygynous households, the direct effect of gender is also small and not significant. But the interaction term is positive and statistically significant and offsets the negative effect of children on women's yields in monogamous households. The opposite sign for polygynous households suggests the specification is not just picking up some effect of childcare on time allocation and productivity. Women in polygynous households are better able to specialize and optimally distribute childcare and farm duties amongst each other, presumably via cooperative arrangements, but women in monogamous households cannot do the same with their husbands. This specification provides additional suggestive evidence supporting the altruism story over other explanations. However, we do not rely too heavily on these results, as fertility may be correlated with efficiency or cooperation in the household and social norms may constrain the amount of childcare that men perform.

\subsection{Selection into Polygyny}


Polygyny is likely correlated with household characteristics such as wealth, capital and family size (Jacoby, 1995; Tertilt, 2005). Household-crop-year fixed effects control for factors that are constant across people in the same household planting the same crop in the same year, but they do not control for factors that are different between husbands and wives, such as propensities for cooperation or varying relative demand for male/female labor. To explore this issue, we take advantage of the ICRISAT survey design. In 1981-83, data on the plots of junior wives were collected only for cotton, cereals, and root crops, which are representative of less than 40 percent of wives' plots. Thus, with the inclusion of household-crop-year fixed effects, the 1981-83 data allow us to examine yield variation on plots planted with the same crop in the same year by the head and his senior wife for all crops but restrict the analysis for junior wives to cotton, cereals, and root crops. In contrast, the 1984-85 data allow us to examine yield variation across all plots, irrespective of crop, planted by the head, senior wife, and junior wives. Thus, if the smaller gender yield differential in polygynous households is driven by either unobserved heterogeneity across household types or greater cooperation between husbands and wives (rather than among co-wives), the effect should still be evident when using 1981-83 data, even when the junior wives’ plots are largely omitted. We find no evidence of this (column I, Table 4); the coefficient on the interaction between female and polygynous is small in magnitude and not statistically significant when we limit the data to 1981-83.

As a further test, we compare polygynous households with different numbers of wives to explore the possibility that households that achieve more efficient allocations are more likely to take on additional wives, in which case.the positive effects of polygyny should be larger for households with more wives. We find no evidence of this; the point estimates for cultivator characteristics interacted with polygyny are not significantly different across households with 
different numbers of wives (columns II and III, Table 4). Despite this, we cannot rule out the possibility of a non-monotonic relationship between number of wives and efficiency or preferences for cooperation (e.g., a threshold effect around exactly two wives).

Although we show above that the effect of polygyny is not simply a scale effect - that is, the addition of an "other" female cultivator is not equivalent to the addition of a wife - polygyny may affect production decisions in ways unrelated to cooperation. For example, multiple wives may be able to meet labor requirements on communal plots more quickly or efficiently, leaving more time for own cultivation. Alternatively, polygyny may increase demands on the husband's time via spousal, familial, or social obligations and reduce the time available for his own cultivation. To examine these possibilities, we split the sample into vertically and horizontallyextended households, each with access to different mechanisms for contract enforcement. We define horizontally-extended households as those that include a brother of the household head and vertically-extended households as those that do not. In vertically-extended households (head with adult children), the head is also the patriarch, and social norms allow him to exert more influence over other household members and enforce greater cooperation. Power dynamics are more complex in horizontally-extended households (head with adult siblings), and the influence of the head may be undermined by coalitions among other household members. If polygyny causes changes in productive arrangements that are not the result of cooperative agreements, then we should observe the same effects in both vertical and horizontal households. Conversely, in our model, polygyny provides greater benefits for households with more limited scope for cooperation (horizontally-extended). While household structure/composition may be endogenous, we can still use this comparison to determine whether there is a common (set of) unobserved characteristic(s) driving male-female yield differentials and selection into polygyny. 
When we split the sample this way (columns IV and V, Table 4), we observe significant effects of polygyny only in horizontally-extended households. Because the same effects are not evident in vertically-extended households where there is already greater scope for cooperation, our main results do not seem to be explained by a reorganization of productive activities outside of cooperative arrangements among cultivators. Among vertically-extended households, we observe no significant yield differences across conjugal status or cultivator type, and the point estimates are generally small in magnitude, consistent with (but not proof of) efficiency in production. This suggests that where the head is able to enforce cooperation among other cultivators, he does so among all cultivators, without preference for certain types or pairs. To the extent production in vertically-extended households is already efficient, our falsification test may lack power as there are no gains to be realized from polygyny. However, this begs the question of why productive efficiency is related to the composition of the household and the relationships among members.

Finally, to examine the possibility that husband-wife yield differentials are driven by endogenous productivity differences between monogamous and polygynous households, we estimate the effect of polygyny on the level of productivity using a household fixed effects specification while including village-crop-year fixed effects. In Panel A of Table 5, polygyny has a negative but not statistically significant effect, suggesting that the transition to polygyny actually reduces yields. In Panel B, we then regress the household fixed effects on household characteristics. ${ }^{23}$ These fixed effects can be interpreted as a measure of the latent productivity of the household, net of plot characteristics and aggregate village-crop-year conditions. Without any controls, the household fixed effect is not significantly different for monogamous and

\footnotetext{
${ }^{23}$ Although identification of the direct effect of polygyny is based on a small sample of 155 plots farmed by only four households that switch from monogamous to polygynous during the survey period, we estimate household fixed effects using the entire sample.
} 
polygynous households or for households that become polygynous. Adding village and time fixed effects increases the magnitude of the polygyny coefficient, and it is now statistically significant, with heads in polygynous households having lower latent productivity than those in monogamous households. Differences in latent productivity are also negative but not statistically significant at the time households become polygynous, suggesting the differences arise over time, rather than being intrinsic. Adding controls for household composition and total cultivated area increases the magnitude of the polygyny coefficient but including capital intensity has no effect (columns III and IV). In summary, we find no evidence of higher latent productivity in polygynous households and suggestive evidence that differences in latent productivity arise over time, perhaps as cooperative arrangements among members develop.

\subsection{Input Use and Unobserved Plot Quality}

If the altruism explanation is correct, we should also find differences in input usage that could explain the observed yield differences among cultivators within a household. Unfortunately, for the years in which we have yield data on all plots cultivated by the household (1984-85), the data on agricultural inputs is limited. Therefore, we are unable to compare male and female labor inputs across the plots of different cultivators, making it difficult to corroborate directly the labor-sharing hypotheses. Using panel Tobit estimation (Honoré, 1992) and controlling for household-crop-year fixed effects, we find weak evidence in Table 6, columns I-III, that women use inputs less intensively. The gender coefficient is negative for labor hours in land improvement (clearing, burning, and bund construction), value of paid labor, and manure, but the point estimates are imprecise. ${ }^{24}$ There are no significant differences for polygynous households.

However, women keep plots fallow for less time and allow fewer years between fallows (columns IV and V, Table 6). Point estimates are of the opposite sign for women in polygynous

\footnotetext{
${ }^{24}$ Input data may be subject to significant measurement error as they are based on recall at the end of each year.
} 
households but not statistically significant. ${ }^{25}$ Fallow differences may point to differences in unobserved plot quality, which would pose a significant threat to our identification strategy. We cannot test directly for differences in unobserved plot quality because plot borders change from year to year, making it impossible to include time-invariant plot fixed effects. Omitting all plot characteristics (size, toposequence, soil type, location) from our preferred specification decreases the magnitude of the coefficients on both the female indicator and the interaction with polygyny, leaving the total effect for women in polygynous households essentially unchanged (column I, Table 7). If we assume observed and unobserved plot characteristics are positively correlated, these results are consistent with higher unobserved plot quality for women, but this does not differ across household types. Moreover, polygyny is found to increase yields equally for wives and other female cultivators, and it is not clear why other female cultivators in polygynous households would also have higher quality plots even though other male cultivators do not.

\subsection{Endogenous Crop Choice}

As seen in the descriptive statistics (Table 1), cropping patterns differ across monogamous and polygynous households and, since household-crop-year fixed effects cannot account for this, it is possible the results could be driven by endogenous planting decisions. To check for this, we first split the data by cereal and non-cereal crops, and it is evident that non-cereal crops are driving the main results (columns II and III, Table 7). For cereal crops, the coefficients on gender and gender interacted with polygyny are smaller in magnitude and neither is statistically significant, while the opposite is true for non-cereal crops. This may reflect stronger social norms governing the pooling of resources in the production of staple foods. However, wives in polygynous households devote a greater share of plots to cereal crops (38 versus 24 percent), so differences

\footnotetext{
${ }^{25}$ These results may also reflect differences in plot history or crop rotation (recall that the fixed effects control only
} for the current crop) if, for example, women tend to farm crops that are less deleterious to soil quality. 
in crop choice would tend to attenuate observed differences in cooperative behavior across monogamous and polygynous households.

We also use an alternative specification (household-year, rather than household-cropyear, fixed effects) to identify gender yield differences from variation across all plots cultivated by the household, rather than only those planted with the same crop. But, because factors such as weather variability may differentially affect certain crops, we also include village-crop-year fixed effects to account for aggregate crop-specific shocks. With this specification, we obtain the same qualitative results in terms of sign and significance, although the point estimates are smaller in magnitude (column IV, Table 7). This suggests that the main results cannot be entirely explained by differences in crop choice across monogamous and polygynous households.

\subsection{Dynamic Inefficiency}

The degree of cooperation in a household affects efficiency, but it can also affect growth via investment choice. Investments with large fixed costs will have higher returns if they can be used across plots controlled by multiple cultivators. Conversely, where there is little opportunity for cooperation, individuals may invest in smaller capital goods or variable inputs that have lower fixed costs and lower returns. We examine household expenditure on large capital investments (plows, scarifiers, weeders, ridgers, line tracers, seeders, sprayers, carts, tractors and draft animals). Because larger and wealthier households are more likely to undertake such investments, we look at investment expenditures as a percent of the household's total expenditure on agricultural inputs. We control for household demographics and land holdings, treating land holdings and polygyny as endogenous. Because both capital investments and polygyny are now at the household level, we can no longer include household fixed effects and 
must instead rely on the use of instrumental variables. As instruments, we use (1) the quantity of land that was acquired via inheritance and (2) the ethnic group of the household.

Although Burkinabé land tenure and property rights follow an informal “customary” system, inherited land is granted to the household for permanent cultivation (Stamm, 1994). The instrument should, therefore, isolate the variation in land area (wealth) that arises from the household's relative position within the lineage, excluding differences due to heterogeneity in skill that are unobserved by the researcher but known to the lineage head. Regarding the second instrument, anthropologists note that polygyny has strong foundations in ethno-cultural traditions (Omariba and Boyle, 2007), while farming practices tended to be quite similar across ethnic groups (Kevane and Grey, 1999). Since ethnic groups tend to be geographically concentrated and, therefore, in differing agro-climatic zones, we also include village- and year- or village-year fixed effects to account for regional and temporal differences. Our key identifying assumption is that expenditures on large capital investments, as a percentage of total farm inputs, are not directly affected by the long-term land allocation decisions of the lineage or the ethnic group of the household, conditional on household composition and village and year fixed effects.

Without using instrumental variables, we find that household landholdings have a significant positive effect on the percentage of agricultural expenditures devoted to large capital goods, while polygyny has no effect (column I, Table 8). In the IV specifications (columns II and III), the coefficient on land holdings is small and not statistically significant. This suggests that asset accumulation, in both land and large capital investments, is driven by unobserved factors, such as ability or endowments. Conversely, the coefficient on polygyny increases in magnitude and becomes statistically significant when instrumental variables are used, suggesting that households who select into polygyny are, in fact, less likely to utilize a capital-intensive 
production process. This is consistent with Tertilt (2005), who suggests that wives may be an alternate form of capital accumulation. Our estimates indicate that polygynous households spend more on large capital goods, as a percentage of their total expenditure on agricultural inputs, which are also goods for which the economic returns are increasing in the scope for cooperative behavior. Tests of over-identification lend support to the validity of our instruments, and the difference between the IV and OLS estimates are as expected. However, we cannot rule out the possibility of a weak instruments problem and, therefore, do not rely too heavily on these estimates. Nonetheless, these results provide additional suggestive evidence to support the altruism hypothesis as, all else equal, we would expect more intensive use of lumpy goods, which are more difficult to sub-divide and share, to be associated with greater inefficiency in input allocation.

\section{Conclusion}

Polygyny creates opportunities for both cooperation and competition. We find that co-wives are more likely to cooperate with one another than with their husband, and our model shows how this can result from selfish behavior rather than altruism. Because of the altruism between husbands and wives, the non-cooperative equilibrium does not differ much from the cooperative equilibrium, making the gains to cooperation greater for co-wives than for husband-wife pairs. Other female cultivators also benefit from polygyny, but cooperation among women is influenced by identity/relationship as well as gender. We do not find evidence of household heads acting as a third-party enforcement mechanism for others' cooperative agreements, except in the context of vertically-extended households, where the head may have greater influence.

Our results do not appear to be driven by selection into polygyny. When junior wives’ plots are excluded from the estimation, we do not observe the same production pattern, 
suggesting the results are driven by interaction among co-wives, rather than fixed characteristics of polygynous households. Analysis of latent productivity measures further reveal that polygynous men tend to have lower latent productivity, and this difference is not intrinsic but arises over time. Moreover, we show that the positive effects of polygyny on efficiency are evident only in a subset of households (horizontally-extended), which suggests our results cannot be explained by other impediments to cooperation, such as social norms or administrative obligations. Additional robustness checks suggest our results are not driven by differences in crop choice or the propensity for cooperation between monogamous and polygynous households. We cannot definitively rule out the possibility of unobserved plot characteristics being correlated with women's yields in polygynous households. But we do not observe differences in women's fallow decisions across the two household types, and the positive effect of polygyny on other female cultivators rules out a simple story about better plot quality for subsequent wives.

Still, as Rangel and Thomas (2012) note, even if endogeneity and measurement issues have been properly accounted for, differences in yields could still be caused by non-convexities in the production process, making non-cooperation even more difficult to confirm. However, since our empirical strategy relies on a comparison of monogamous and polygynous households, it is sufficient to note that these other unobserved factors cannot be driving our results unless they differ across monogamous and polygynous households. Given the diversity of household structure in Burkina Faso and our finding that co-wives are able to minimize yield differentials more than any other cultivator pair, it seems unlikely that only polygynous households would have access to the markets, technologies, and strategies that reduce yield differentials, and that these mechanisms are available only to the female cultivators in the household. 
Altruism can facilitate cooperation by reducing transaction costs, improving information flows and ensuring repeat interaction. However, we show that, all else equal, altruism can also inhibit cooperation by increasing payoffs in the non-cooperative equilibrium and/or limiting the scope for (credible) punishment. Although we use the unique case of polygynous households to test this hypothesis, there are many situations in which our findings may be relevant. For example, trade agreements between countries that have contentious relationships may be more generous than those between friendly countries because shared political interests (a type of altruism) ensure amicable negotiations, even in the absence of an explicit agreement. The adage about never mixing business with family also seems to be rooted in the problems created specifically by altruistic linkages. Our findings imply that there may be some optimal social distance that could be leveraged to improve program outcomes by targeting groups of individuals who belong to the same social network but are not directly connected (e.g., joint liability groups for microcredit, early adopters of new technologies, peer groups in school and the workplace).

\section{References}

Abreu, D., D. Pearce, and E. Stachetti. 1993. "Renegotiation and Symmetry in Repeated Games.” Journal of Economic Theory, 60(2): 217-240.

Akresh, R. 2008. “(In) Efficiency in Intrahousehold Allocations.” IZA Discussion Paper No. 1858.

Akresh, R., J. Chen and C. Moore. 2012. "Productive Efficiency and the Scope for Cooperation in Polygynous Households.” American Journal of Agricultural Economics, 94(2): 395-401.

Becker, G.S. 1981. "Altruism in the Family and Selfishness in the Market Place.” Economica, 48(189): 1-15.

Bergstrom, T., L. Blume and H. Varian. 1986. "On the Private Provision of Public Goods.” Journal of Public Economics, 29(1): 25-49.

Bernheim, B.D., B. Peleg, and M. Whinston. 1987. "Coalition-Proof Nash Equilibria I. Concepts.” Journal of Economic Theory, 42(1): 1-12. 
Bernheim, B.D., and O. Stark. 1988. "Altruism within the Family Reconsidered: Do Nice Guys Finish Last?” American Economic Review, 78(5): 1034-1045.

Bobonis, G. J. 2009. "Is the Allocation of Resources within the Household Efficient? New Evidence from a Randomized Experiment.” Journal of Political Economy 117(3): 453-503.

Boye, A., K. Hill, S. Isaacs, and D. Gordis. 1991. "Marriage Law and Practice in the Sahel.” Studies in Family Planning, 22(6): 343-349.

Browning, M., and P.A. Chiappori. 1998. "Efficient Intra-Household Allocations: A General Characterization and Empirical Tests.” Econometrica, 66(6): 1241-1278.

Chiappori, P.A., Fortin, B. and G. Lacroix. 2002. "Marriage Market, Divorce Legislation, and Household Labor Supply.” Journal of Political Economy, 110(1): 37-72.

Dey Abbas, J. 1997. "Gender Asymmetries in Intrahousehold Resource Allocation in SubSaharan Africa: Some Policy Implications for Land and Labor Productivity.” In L. Haddad, J. Hoddinott, and H. Alderman, eds. Intrahousehold Resource Allocation in Developing Countries: Models, Methods, and Policy. Baltimore, MD: Johns Hopkins University Press, 249-262.

Diallo, N. N., and J. G. Nagy. 1986. "Burkina Faso: Access and Control of Resources in the Farming System: Recent Legal, Political and Socio-Economic Changes.” Presented at the Conference on Gender Issues in Farming Systems Research and Extension, Gainesville, Florida. February 26-March 1.

Dubois, P. and E. Ligon. 2010. "Nutrition and Risk Sharing within the Household.” CUDARE Working Paper Series 1096, Department of Agricultural and Resource Economics and Policy, University of California, Berkeley.

Duflo, E. and C. Udry. 2004. "Intrahousehold Resource Allocation in Côte d'Ivoire: Social Norms, Separate Accounts and Consumption Choices.” National Bureau of Economic Research Working Paper 10498.

Fafchamps, M. 1993. "Sequential Labor Decisions Under Uncertainty: an Estimable Household Model of West African Farmers." Econometrica, 61(5): 1173-1197.

Fafchamps, M. 2001. “Intrahousehold Access to Land and Sources of Inefficiency.” In A. de Janvry, G. Gordillo, E. Sadoulet, and J. P. Platteau, eds. Access to Land, Rural Poverty, and Public Action. Oxford: Oxford University Press.

Fehr, E. and K. Schmidt. 2006. “The Economics of Fairness, Reciprocity and Altruism Experimental Evidence and New Theories.” In S-C. Kolm and J. M. Ythier, eds. Handbook on the Economics of Giving, Reciprocity and Altruism, Volume 1. Amsterdam: Elsevier, 615691. 
Foster, A. and M. Rosenzweig. 2001. "Imperfect Commitment, Altruism, and the Family: Evidence from Transfer Behavior in Low Income Rural Areas.” Review of Economics and Statistics, 83(3): 389-407.

Friedman, J. 1971. “A Non-cooperative Equilibrium for Supergames.” The Review of Economic Studies, 38(1): 1-12.

Goldstein, M., and C. Udry. 2008. "The Profits of Power: Land Rights and Agricultural Investment in Ghana.” Journal of Political Economy, 116(6): 981-1022.

Guyer, J. 1986. ”Intrahousehold Processes and Farming Systems Research: Perspectives from Anthropology." In J.L. Moock, ed. Understanding Africa's Rural Households and Farming Systems, Boulder, CO: Westview Press, 92-104.

Honoré, B. 1992. "Trimmed LAD and Least Squares Estimation of Truncated and Censored Regression Models with Fixed Effects.” Econometrica, 60(3): 533-565.

Jacoby, H. 1995. "The Economics of Polygyny in Sub-Saharan Africa: Female Productivity and the Demand for Wives in Côte d'Ivoire.” Journal of Political Economy, 103(5): 938-971.

Jankowiak, W., M. Sudakov, and B.C. Wilreker. 2005. "Co-Wife Conflict and Co-operation.” Ethnology, 44(1): 81-98.

Kazianga, H., and S. Klonner. 2009. "The Intra-household Economics of Polygyny: Fertility and Child Mortality in Rural Mali.” MPRA Paper No. 12859.

Kazianga, H., and Z. Wahhaj. 2013. "Gender, Social Norms and Household Production in Burkina Faso.” Economic Development and Cultural Change, 61(3): 539-576.

Kevane, M., and L. Gray. 1999. “A Woman’s Field is Made at Night: Gendered Land Rights and Norms in Burkina Faso.” Feminist Economics, 5(3): 1-26.

Lundberg, S., and R. Pollak. 1993. "Separate Spheres Bargaining and the Marriage Market.” Journal of Political Economy, 101(6): 988-1010.

Mammen, K., 2009. “All for One or Each for Her Own: Do Polygamous Families Share and Share Alike?” Mimeo, Columbia University.

Matlon, P. J. 1988. "The ICRISAT Burkina Faso Farm-Level Studies: Survey Methods and Data Files.” Village Level Studies and Miscellaneous Paper Series, ICRISAT.

Omariba, D. W. R. and M. H. Boyle. 2007. "Family Structure and Child Mortality in SubSaharan Africa: Cross-National Effects of Polygyny." Journal of Marriage and Family, 69(2): 528-543. 
Peterman, A., A. Quisumbing, J. Berhman, and E. Nkonya. 2011. "Understanding the Complexities Surrounding Gender Differences in Agricultural Productivity in Nigeria and Uganda.” Journal of Development Studies, 47(10): 1482-1509.

Rangel, M., and D. Thomas. 2012. "Gender, Production and Consumption: Allocative Efficiency within Farm Households.” Mimeo, Princeton University.

Saito, K. 1994. "Raising the Productivity of Women Farmers in Sub-Saharan Africa.” World Bank Discussion Paper No. 230.

Stamm, V. 1994. "Non-Commercial Systems of Land Allocation and Their Economic Implications: Evidence from Burkina Faso.” Journal of Modern African Studies, 32(4): 713717.

Stock, J. and M. Yogo. 2005. “Testing for Weak Instruments in Linear IV Regression.” in J.H. Stock and D.W.K. Andrews (eds). Identification and Inference for Econometric Models: Essays in Honor of Thomas J. Rothenberg, Cambridge University Press.

Tertilt, M. 2005. “Polygyny, Fertility, and Savings.” Journal of Political Economy, 113 (6): 1341-1371.

Thorsen, D. 2002. “'We Help our Husbands!' Negotiating the Household Budget in Rural Burkina Faso.” Development and Change, 33(1): 129-146.

Udry, C. 1996. "Gender, Agricultural Production, and the Theory of the Household.” Journal of Political Economy, 104(5): 1010-1046.

van Koppen, B. 1990. "Women and the Design of Irrigation Schemes: Experiences from Two Cases in Burkina Faso.” Paper presented at the International Workshop on Design for Sustainable Farmer-Managed Irrigation Schemes in Sub-Saharan Africa, Wageningen Agricultural University, The Netherlands, 5-8 February.

Warr, P. 1983. "The Private Provision of a Public Good Is Independent of the Distribution of Income.” Economic Letters, 13(2-3): 207-11. 
Table 1. Yield, Area and Primary Crop, by Plot, Household Type and Cultivator

\begin{tabular}{|c|c|c|c|c|c|c|c|c|}
\hline & \multicolumn{4}{|c|}{ Monogamous } & \multicolumn{4}{|c|}{ Polygynous } \\
\hline & $\begin{array}{l}\text { Household } \\
\text { Head }\end{array}$ & $\begin{array}{c}\text { Wife of } \\
\text { Head }\end{array}$ & $\begin{array}{l}\text { Other } \\
\text { Male }\end{array}$ & $\begin{array}{l}\text { Other } \\
\text { Female }\end{array}$ & $\begin{array}{l}\text { Household } \\
\text { Head }\end{array}$ & $\begin{array}{c}\text { Wife of } \\
\text { Head }\end{array}$ & $\begin{array}{l}\text { Other } \\
\text { Male }\end{array}$ & $\begin{array}{l}\text { Other } \\
\text { Female }\end{array}$ \\
\hline Yield (1000 FCFA) & $\begin{array}{l}126.29 \\
(651.6)\end{array}$ & $\begin{array}{c}49.15 \\
(267.0)\end{array}$ & $\begin{array}{l}142.93 \\
(498.2)\end{array}$ & $\begin{array}{l}124.82 \\
(434.7)\end{array}$ & $\begin{array}{c}85.47 \\
(341.3)\end{array}$ & $\begin{array}{l}59.50 \\
(208.4)\end{array}$ & $\begin{array}{l}145.51 \\
(358.6)\end{array}$ & $\begin{array}{c}71.57 \\
(250.6)\end{array}$ \\
\hline $\begin{array}{l}\text { Average Plot Size } \\
\text { (hectare) }\end{array}$ & $\begin{array}{l}0.748 \\
(1.24)\end{array}$ & $\begin{array}{l}0.075 \\
(0.13)\end{array}$ & $\begin{array}{l}0.318 \\
(0.54)\end{array}$ & $\begin{array}{l}0.069 \\
(0.12)\end{array}$ & $\begin{array}{l}0.756 \\
(1.14)\end{array}$ & $\begin{array}{l}0.099 \\
(0.14)\end{array}$ & $\begin{array}{l}0.385 \\
(0.48)\end{array}$ & $\begin{array}{l}0.074 \\
(0.10)\end{array}$ \\
\hline Observations & 743 & 425 & 172 & 319 & 1156 & 1305 & 407 & 699 \\
\hline \multicolumn{9}{|c|}{ Percentage of Plots Planted with a Given Primary Crop } \\
\hline Millet & 27.05 & 9.18 & 25.00 & 7.52 & 18.94 & 11.42 & 13.51 & 6.58 \\
\hline White Sorghum & 20.46 & 8.71 & 19.77 & 10.66 & 22.92 & 21.30 & 29.73 & 12.45 \\
\hline Red Sorghum & 8.48 & 4.00 & 4.65 & 6.58 & 10.73 & 3.60 & 5.65 & 4.15 \\
\hline Maize & 17.50 & 2.35 & 8.72 & 0.94 & 15.57 & 2.15 & 8.60 & 3.72 \\
\hline Groundnuts & 4.44 & 18.35 & 8.72 & - & 6.14 & 18.62 & 10.32 & - \\
\hline Okra & 0.81 & 21.65 & 1.74 & 18.18 & 0.35 & 15.33 & - & 17.02 \\
\hline Cotton & 7.67 & 1.65 & 17.44 & 1.57 & 9.95 & 1.00 & 22.60 & 1.86 \\
\hline Earthpeas/Fonio & 1.62 & 28.23 & 2.32 & 36.05 & 1.04 & 19.08 & 1.72 & 45.21 \\
\hline Others & 11.97 & 5.89 & 11.62 & 18.48 & 14.38 & 7.51 & 7.88 & 9.01 \\
\hline
\end{tabular}

Note: Standard deviations in parentheses. Data source: 1984-85 ICRISAT Burkina Faso survey. During 1984-85, the average exchange rate was approximately US \$1 = 441 FCFA. 
Table 2. Fixed Effects Estimates of the Effect of Cultivator Characteristics on Plot Yield ${ }^{a}$

\begin{tabular}{|c|c|c|c|c|}
\hline & $(\mathrm{I})$ & (III) & $\overline{(1 \mathrm{III})^{\mathrm{b}}}$ & $(\mathrm{IIV})^{\mathrm{b}}$ \\
\hline \multirow[t]{2}{*}{ Gender (1=female) } & $-74.51 * * *$ & $-87.69 * * *$ & $-202.21 * * *$ & -45.46 \\
\hline & (15.39) & $(18.14)$ & (34.14) & (50.68) \\
\hline \multirow[t]{2}{*}{ Other Male } & & $-40.49 * *$ & $-97.18 * *$ & \\
\hline & & $(20.41)$ & (39.38) & \\
\hline \multirow[t]{2}{*}{ Other Female } & & -12.77 & -31.96 & \\
\hline & & $(15.37)$ & (31.39) & \\
\hline \multirow{2}{*}{\multicolumn{2}{|c|}{ Gender*Number of Kids }} & & & $-23.28 * *$ \\
\hline & & & & (10.27) \\
\hline \multirow[t]{2}{*}{ Gender*Polygynous } & & & $168.94 * * *$ & 41.94 \\
\hline & & & $(40.09)$ & $(64.85)$ \\
\hline \multirow{2}{*}{\multicolumn{2}{|c|}{ Other Male*Polygynous }} & & $86.50 *$ & \\
\hline & & & $(45.82)$ & \\
\hline \multirow{2}{*}{\multicolumn{2}{|c|}{ Other Female*Polygynous }} & & 28.71 & \\
\hline & & & $(35.81)$ & \\
\hline \multirow{2}{*}{\multicolumn{3}{|c|}{ Gender*Polygynous*Number of Kids }} & & $22.15 *$ \\
\hline & & & & $(11.62)$ \\
\hline Observations & 5230 & 5230 & 5230 & 4701 \\
\hline
\end{tabular}

Notes: Standard errors in parentheses. $\left({ }^{* * *}\right),\left({ }^{* *}\right)$ and $\left({ }^{*}\right)$ denote significance at the $1 \%, 5 \%$ and $10 \%$ levels, respectively. All specifications include household-crop-year fixed effects and controls for plot size (by decile), soil type, toposequence and location. Data source: 1984-85 ICRISAT Burkina Faso Survey. ${ }^{a}$ Calculated as value of plot output per hectare.

${ }^{b}$ Includes interactions of all plot characteristics with the indicator for polygyny. 
Table 3. Fixed Effects Estimates of the Effect of Cultivator Characteristics on Plot Yield ${ }^{\text {a }}$, Pairwise Groupings

\begin{tabular}{|c|c|c|c|c|c|}
\hline & $\begin{array}{l}\text { Head and } \\
\text { Wives } \\
\text { (I) }\end{array}$ & $\begin{array}{c}\text { Other } \\
\text { Cultivators } \\
\text { (II) }\end{array}$ & $\begin{array}{l}\text { Men Only } \\
\text { (III) }\end{array}$ & $\begin{array}{l}\text { Women Only } \\
\text { (IV) }\end{array}$ & $\begin{array}{c}\text { Head and } \\
\text { Wives } \\
\text { (V) }\end{array}$ \\
\hline Gender (1=female) & $\begin{array}{l}-151.97^{* * *} \\
(40.47)\end{array}$ & $\begin{array}{l}-160.72 * * * \\
(54.01)\end{array}$ & & & $\begin{array}{r}-63.60 \\
(66.14)\end{array}$ \\
\hline Gender*Add'I Female ${ }^{b}$ & & & & & $\begin{array}{l}-132.29 * \\
(78.33)\end{array}$ \\
\hline Other Male & & & $\begin{array}{l}-74.78 * * \\
(36.06)\end{array}$ & & \\
\hline Other Female & & & & $\begin{array}{r}18.16 \\
(20.77)\end{array}$ & \\
\hline Gender*Polygynous & $\begin{array}{l}118.52 \text { ** } \\
(47.32)\end{array}$ & $\begin{array}{l}131.04^{* *} \\
(61.80)\end{array}$ & & & $\begin{array}{r}33.67 \\
(75.20)\end{array}$ \\
\hline Gender* Poly*Add'I Female & & & & & $\begin{array}{r}126.61 \\
(88.86)\end{array}$ \\
\hline Other Male*Polygynous & & & $\begin{array}{c}69.99 * \\
(42.05)\end{array}$ & & \\
\hline Other Female*Polygynous & & & & $\begin{array}{r}-18.87 \\
(23.23)\end{array}$ & \\
\hline Observations & 3629 & 1597 & 2478 & 2748 & 3629 \\
\hline
\end{tabular}

Notes: Standard errors in parentheses. $\left({ }^{* * *}\right),\left({ }^{* *}\right)$ and $\left({ }^{*}\right)$ denote significance at the $1 \%, 5 \%$ and $10 \%$ levels, respectively. All specifications include household-crop-year fixed effects and controls for plot size (by decile), soil type, toposequence, location and interactions with polygyny.

Data source: 1984-85 ICRISAT Burkina Faso Survey.

${ }^{a}$ Calculated as value of plot output per hectare.

${ }^{\mathrm{b}}$ Additional Female equal to one if there is an other female cultivator present in the household. 
Table 4. Fixed Effects Estimates of the Effect of Cultivator Characteristcs on Plot Yield ${ }^{\text {a }}$, Alternate Samples

\begin{tabular}{|c|c|c|c|c|c|}
\hline & $\begin{array}{c}\text { 1981-83 } \\
\text { Only } \\
(\mathrm{I})\end{array}$ & $\begin{array}{c}\text { Polygynous } \\
=2 \text { Wives } \\
\text { (II) }\end{array}$ & $\begin{array}{c}\text { Polygynous } \\
>2 \text { Wives } \\
\text { (III) }\end{array}$ & $\begin{array}{c}\text { Vertical }^{\mathrm{b}} \\
\text { (IV) }\end{array}$ & $\begin{array}{c}\text { Horizontal }^{\mathrm{c}} \\
(\mathrm{V})\end{array}$ \\
\hline Gender (1=female) & $\begin{array}{l}-35.13^{* * *} \\
(12.48)\end{array}$ & $\begin{array}{l}-155.14^{* * *} \\
(40.11)\end{array}$ & $\begin{array}{l}-155.14^{* * *} \\
(39.01)\end{array}$ & $\begin{array}{r}-8.43 \\
(21.02)\end{array}$ & $\begin{array}{l}-516.33 * * * \\
(111.29)\end{array}$ \\
\hline Other Male & $\begin{array}{l}-30.30 * * \\
(12.58)\end{array}$ & $\begin{array}{r}-56.35 \\
(47.21)\end{array}$ & $\begin{array}{r}-56.35 \\
(45.91)\end{array}$ & $\begin{array}{r}-18.55 \\
(25.80)\end{array}$ & $\begin{array}{l}-237.79 * * \\
(109.52)\end{array}$ \\
\hline Other Female & $\begin{array}{r}2.74 \\
(15.60)\end{array}$ & $\begin{array}{r}-16.02 \\
(36.50)\end{array}$ & $\begin{array}{l}-16.02 \\
(35.49)\end{array}$ & $\begin{array}{r}-22.94 \\
(20.73)\end{array}$ & $\begin{array}{r}-5.00 \\
(74.17)\end{array}$ \\
\hline Gender*Polygynous & $\begin{array}{r}1.66 \\
(14.88)\end{array}$ & $\begin{array}{l}136.33 * * \\
(53.59)\end{array}$ & $\begin{array}{l}154.32 * * * \\
(53.01)\end{array}$ & $\begin{array}{r}-9.68 \\
(26.50)\end{array}$ & $\begin{array}{l}518.79 * * * \\
(117.88)\end{array}$ \\
\hline Other Male*Polygynous & $\begin{array}{r}17.15 \\
(15.25)\end{array}$ & $\begin{array}{r}72.42 \\
(62.19)\end{array}$ & $\begin{array}{r}45.40 \\
(62.09)\end{array}$ & $\begin{array}{r}8.06 \\
(34.52)\end{array}$ & $\begin{array}{l}251.77 * * \\
(116.05)\end{array}$ \\
\hline Other Female*Polygynous & $\begin{array}{r}-23.77 \\
(18.53)\end{array}$ & $\begin{array}{r}14.76 \\
(48.07)\end{array}$ & $\begin{array}{r}13.91 \\
(44.86)\end{array}$ & $\begin{array}{r}20.62 \\
(27.05)\end{array}$ & $\begin{array}{r}2.30 \\
(78.45)\end{array}$ \\
\hline Observations & 4198 & 3112 & 3142 & 2878 & 1823 \\
\hline
\end{tabular}

Notes: Standard errors in parentheses. $\left({ }^{* * *}\right),\left({ }^{* *}\right)$ and $\left({ }^{*}\right)$ denote significance at the $1 \%, 5 \%$ and $10 \%$ levels, respectively. All specifications include household-crop-year fixed effects and controls for plot size (by decile), soil type, toposequence, location and interactions with polygyny.

Data source: 1981-85 ICRISAT Burkina Faso Survey.

${ }^{a}$ Calculated as value of plot output per hectare.

${ }^{b}$ Excludes households that contain a brother of the household head.

Includes only households that contain a brother of the household head. 
Table 5. Fixed Effects Estimates of the Effect of Polygyny on Plot Yield

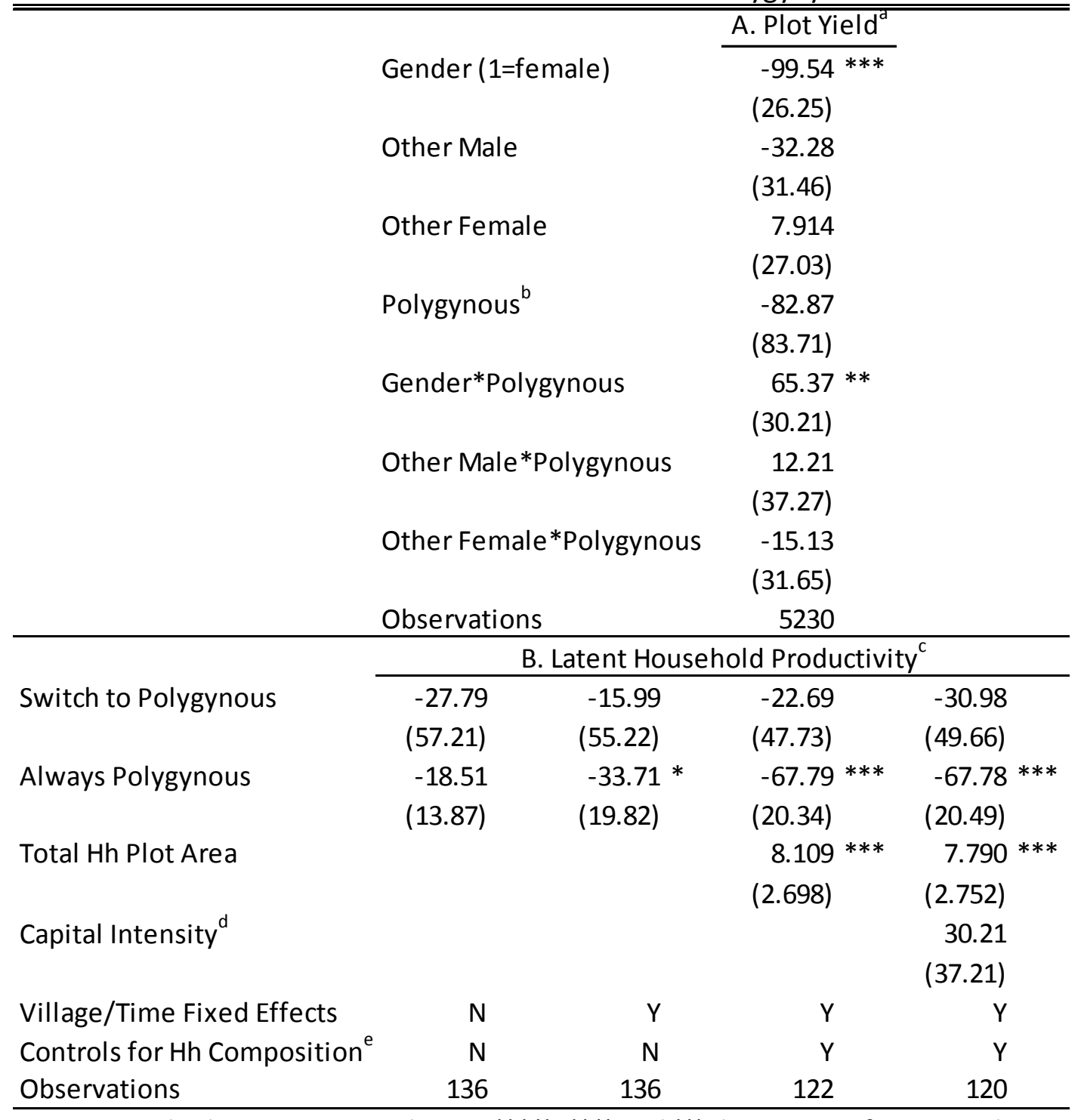

Notes: Standard errors in parentheses. $\left({ }^{* * *}\right),\left({ }^{* *}\right)$ and $\left({ }^{*}\right)$ denote significance at the $1 \%, 5 \%$ and $10 \%$ levels, respectively. Panel $A$ includes household fixed effects, villagecrop-year fixed effects and controls for plot size (by decile), soil type, toposequence, location and interactions with polygyny.

Data source: 1984-85 ICRISAT Burkina Faso Survey.

${ }^{a}$ Calculated as value of plot output per hectare.

birect effect of polygyny, conditional on household fixed effect, identified from households that switch from monogamous to polygynous during the survey period. 'Dependent variable is the household fixed effect estimated in Panel A.

${ }^{d}$ Defined as share of total expenditure on agricultural inputs devoted to large capital goods (plows, scarifiers, weeders, ridgers, line tracers, seeders, sprayers, carts, tractors, draft animals).

${ }^{\mathrm{e}}$ Number of individuals in nine age-sex categories, excluding females age 17-54. 
Table 6. Panel Tobit Fixed Effects Estimates of Input Choice

\begin{tabular}{|c|c|c|c|c|c|}
\hline Dependent Variable & $\begin{array}{l}\text { Hours in Land } \\
\text { Improvement }^{\mathrm{a}} \\
\text { (Per Hectare) } \\
\text { (I) }\end{array}$ & $\begin{array}{c}\text { Paid Labor } \\
\text { (1000 FCFA } \\
\text { Per Hectare) } \\
\text { (II) }\end{array}$ & $\begin{array}{c}\text { Manure } \\
\text { (1000 Kg Per } \\
\text { Hectare) } \\
\text { (III) }\end{array}$ & $\begin{array}{l}\text { Length of } \\
\text { Fallow } \\
\text { (IV) }\end{array}$ & $\begin{array}{c}\text { Years Since } \\
\text { Fallow } \\
\text { (V) }\end{array}$ \\
\hline \multirow[t]{2}{*}{ Gender (1=female) } & -12.89 & -2.27 & -2.69 & $-3.82 * * *$ & $-6.73 * * *$ \\
\hline & $(26.20)$ & (2.29) & (3.79) & $(1.04)$ & $(2.20)$ \\
\hline \multirow[t]{2}{*}{ Other Male } & -10.82 & -5.97 & -5.57 & $-2.12 *$ & $-9.48 * *$ \\
\hline & $(27.43)$ & (5.01) & $(5.32)$ & $(1.20)$ & (3.99) \\
\hline \multirow[t]{2}{*}{ Other Female } & 14.78 & -10.03 & 15.45 & -0.25 & 2.73 \\
\hline & (33.66) & (6.11) & (25.12) & (1.08) & $(2.14)$ \\
\hline \multirow[t]{2}{*}{ Gender*Polygynous } & 24.99 & 2.25 & -4.04 & 1.79 & 1.31 \\
\hline & (28.17) & (3.15) & $(5.46)$ & $(1.15)$ & $(2.32)$ \\
\hline \multirow[t]{2}{*}{ Other Male*Polygynous } & -34.60 & 0.39 & -3.03 & 1.50 & 2.34 \\
\hline & $(33.34)$ & (5.49) & (6.17) & $(1.35)$ & $(4.03)$ \\
\hline \multirow[t]{2}{*}{ Other Female*Polygynous } & $-90.97 *$ & 8.99 & -21.45 & 0.26 & -3.21 \\
\hline & $(48.54)$ & (6.53) & (25.91) & $(1.20)$ & $(2.33)$ \\
\hline Mean & 6.94 & 0.85 & 1.17 & 10.24 & 11.15 \\
\hline Mean if $>0$ & 62.74 & 5.30 & 9.30 & & 14.58 \\
\hline Observations & 5172 & 5230 & 5172 & 3076 & 4356 \\
\hline
\end{tabular}

Notes: Standard errors in parentheses. $\left({ }^{* * *}\right),\left({ }^{* *}\right)$ and $\left({ }^{*}\right)$ denote significance at the $1 \%, 5 \%$ and $10 \%$ levels, respectively. All specifications include household-crop-year fixed effects and controls for plot size (by decile), soil type, toposequence, location and interactions with polygyny.

Data source: 1984-85 ICRISAT Burkina Faso Survey.

a Land improvement refers to clearing, burning and bund construction.

${ }^{b}$ Linear regression with fixed effects, as values are recorded conditional on fallowing. 
Table 7. Fixed Effects Estimates of the Effect of Cultivator Characteristics on Plot Yield ${ }^{\text {a }}$, Alternate Specifications

\begin{tabular}{lcccc}
\hline \hline & No Plot & & & \multicolumn{2}{c}{ Hh-Year } \\
& Chars. & Cereals & Non-Cereals & Fixed Effects \\
& $(\mathrm{I})$ & $(\mathrm{II})$ & $(\mathrm{III})$ & $(\mathrm{IV})$ \\
\cline { 2 - 5 } Gender (1=female) & $-125.67 * * *$ & -51.61 & $-482.87 * * *$ & $-108.12 * * *$ \\
& $(31.15)$ & $(32.91)$ & $(74.50)$ & $(25.97)$ \\
Other Male & -8.52 & $-92.94 * *$ & -83.43 & $-58.48 *$ \\
& $(36.98)$ & $(37.39)$ & $(82.15)$ & $(31.45)$ \\
Other Female & -3.58 & $-70.15^{*}$ & -23.15 & -13.57 \\
& $(31.80)$ & $(36.17)$ & $(51.06)$ & $(26.85)$ \\
Gender*Polygynous & $128.65 * * *$ & 10.01 & $452.14 * * *$ & $74.53 * *$ \\
& $(35.90)$ & $(38.45)$ & $(86.90)$ & $(29.84)$ \\
Other Male*Polygynous & 21.09 & $84.15 *$ & 63.75 & 35.70 \\
& $(43.12)$ & $(43.47)$ & $(95.29)$ & $(37.09)$ \\
Other Female*Polygynous & 6.01 & 68.88 & 17.24 & 5.470 \\
& $(36.33)$ & $(42.36)$ & $(57.24)$ & $(31.37)$ \\
Observations & 5230 & 2923 & 2307 & 5230 \\
\hline
\end{tabular}

Notes: Standard errors in parentheses. $\left({ }^{* * *}\right),\left({ }^{* *}\right)$ and $\left({ }^{*}\right)$ denote significance at the $1 \%, 5 \%$ and $10 \%$ levels, respectively. All specifications include household-crop-year fixed effects (unless otherwise noted) and controls for plot size (by decile), soil type, toposequence, location, and interactions with polygyny.

Data source: 1984-85 ICRISAT Burkina Faso Survey.

${ }^{a}$ Calculated as value of plot output per hectare.

${ }^{b}$ Also includes village-crop-year fixed effects. 
Table 8. Instrumental Variables Estimates of the Effect of Polygyny on Capital Intensity

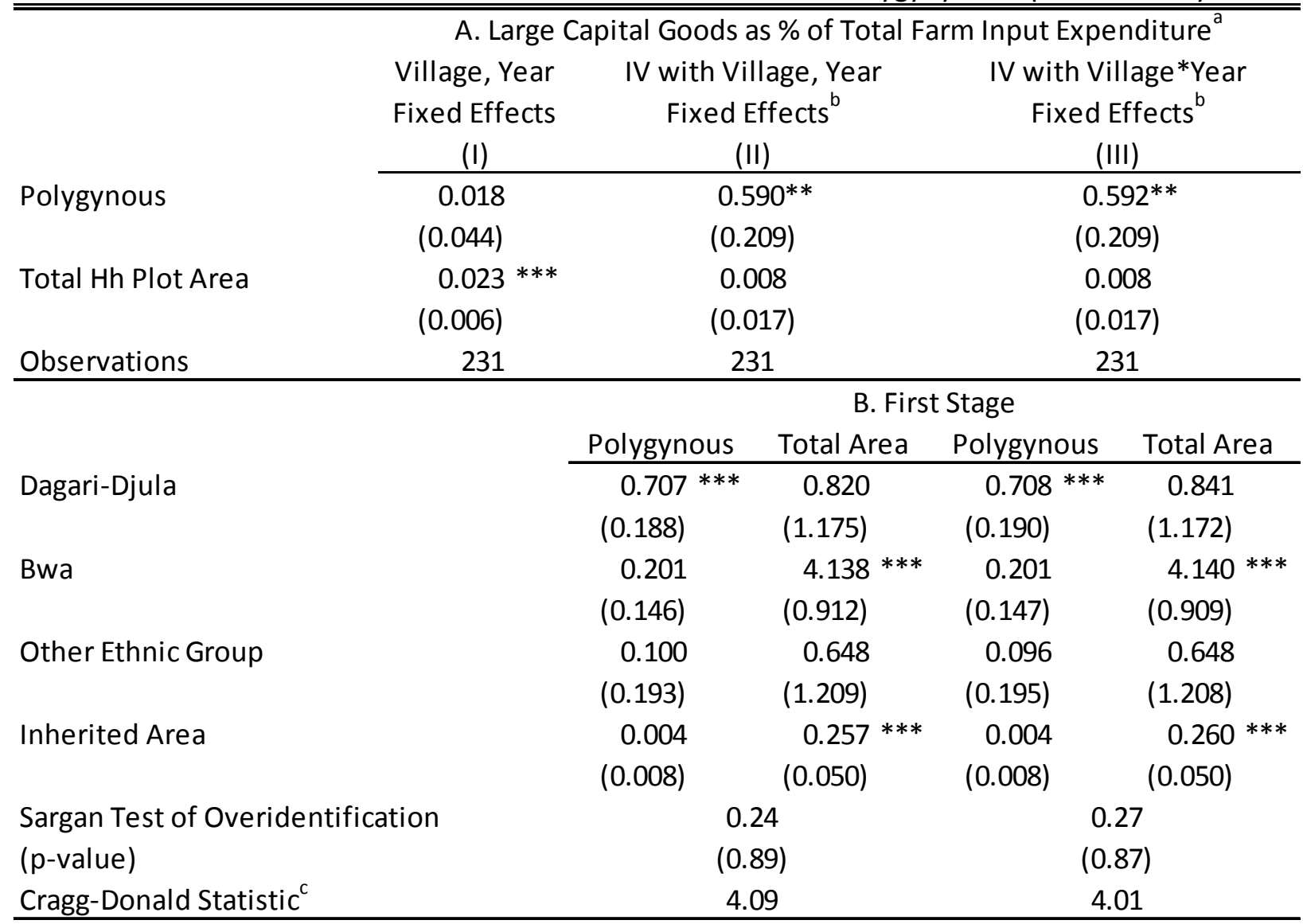

Notes: Standard errors in parentheses. $\left({ }^{* * *}\right),\left({ }^{* *}\right)$ and $\left({ }^{*}\right)$ denote significance at the $1 \%, 5 \%$ and $10 \%$ levels, respectively. All specifications include controls for household composition.

Data source: 1984-85 ICRISAT Burkina Faso Survey.

ancludes plows, scarifiers, weeders, ridgers, line tracers, seeders, sprayers, carts, tractors and draft animals.

bolygynyous and total household plot area treated as endogenous. Instruments include ethnic group ("other" includes Rimaibe, Fulani/Peulh, Fulse/Kurumba, Mossi and Dafing/Marka; "Southern" Fulani/Peulh Mossi is the excluded category) and hectares of inherited land.

'Based on Stock and Yogo (2005). 